\title{
Empirical Study of Treatment of Sour Gas by New Technology
}

\author{
Mehdi Zarifian Jenadelh ${ }^{1}$, Farshad Farahbod ${ }^{2, ~ *}$ \\ ${ }^{1}$ Dpartment of Chemical Engineering, Sirjan Branch, Islamic Azad University, Sirjan, Iran \\ ${ }^{2}$ Department of Chemical Engineering, Firoozabad Branch, Islamic Azad University, Firoozabad, Iran
}

\section{Email address:}

f.farahbod@iauf.ac.ir( F. Farahbod),mf_fche@yahoo.com(F. Farahbod)

${ }^{*}$ Corresponding author

\section{To cite this article:}

Mehdi Zarifian Jenadelh, Farshad Farahbod. American Journal of Chemical Engineering. Vol. 5, No. 1, 2017, pp. 1-5. doi: $10.11648 /$ j.ajche.20170501.11

Received: September 22, 2016; Accepted: January 7, 2017; Published: February 3, 2017

\begin{abstract}
The use of multistage, fluidized beds of continuous recycles reveals economically and technically attractive for both adsorption of stack gas $\mathrm{SO}_{2}$ and sequential conversion to elemental sulfur. This paper studies the adsorption process behavior of $\mathrm{SO}_{2}$ removal in one bed reactor which is filled with zinc oxide nano catalysts. The performance of catalytic bed is analyzed experimentally and theoretically by measuring the rate of mass transfer, NA, in this work. Sulfur elimination from gas is the major purpose of the handled experiments. The specific surface area $\left(15,20\right.$ and $\left.25 \mathrm{~m}^{2} / \mathrm{m}^{3}\right)$ as a effective parameter on mass transfer area and the particle diameter (40,60 and $80 \mathrm{~nm}$ ) as feed driving force on the amount of NA are evaluated.
\end{abstract}

Keywords: $\mathrm{SO}_{2}$ Removal, Experimental and Theoretical Study, Catalytic Bed, Sulfur

\section{Introduction}

The primary and essential difference between regular gas and "sour" gas is the presence of a sulphur compounds. In very low concentrations, less than 1 part of gas in a million parts of air $(<1 \mathrm{ppm})$, it has a characteristic odor like that of rotten eggs. In high concentrations, it has other important characteristics. The sulphur compounds are extremely toxic. A major factor in its toxicity is its ability to fatigue the sense of smell. The sulphur compounds loses the typical rotten eggs odor when the concentration rises, and exposed workers may not be aware of increased gas concentrations. The exposure to concentrations above $600 \mathrm{ppm}$ can be rapidly fatal. It causes extreme corrosion. Corrosion of pipes, valves and fittings can cause a breakdown of gas and oil gathering systems and be a serious threat to employees and the public. The gas is flammable and forms explosive mixtures in a range of $4.3 \%$ to $45.5 \%$ by volume in air. The following information deals primarily with the toxicity of sulphur compounds. Dismayed by a number of deaths resulting from hydrogen sulfide, the seriousness of the hazard can be explained in the following way:
1. "The toxicity and rapidity of death from exposure to hydrogen sulfide approaches that of hydrogen cyanide.

Cyanides have had better 'press' coverages than the sulfides. If states had exacted the death penalty by the use of hydrogen sulfide rather than hydrogen cyanide, we might have greater respect for the hydrogen sulfide hazard."

2. "Exposure to hydrogen sulfide rapidly produces olfactory fatigue!

Stated more simply, it puts your nose 'out of business'. From then on, odor is no longer an indicator of the hazard and gas concentrations may increase to a hazardous level with no detectable change. The exposed individual loses the ability to gauge exposure.

3. "Comparing the effects of hydrogen sulfide to the effects of ethyl alcohol (the active ingredient in bourbon, scotch, gin, beer, etc.!):

If you inhale ethyl alcohol vapors in a concentration of $1000 \mathrm{ppm}(0.1 \%$ by volume) for eight hours, you may get drunk. If you inhale hydrogen sulfide in a concentration of $1000 \mathrm{ppm}(0.1 \%$ by volume $)$ for only a few seconds, you will be dead."

The use of multistage, fluidized beds of continuous 
recycles reveals economically and technically attractive for both adsorption of stack gas $\mathrm{SO}_{2}$ and sequential conversion to elemental sulfur. Carlos et al. in 2013, studied the effect of oxy firing of different lignite in fluidized bed combustor on $\mathrm{SO}_{2}$ and $\mathrm{NO}_{x}$ emissions, experimentally. Results were compared with the amount of $\mathrm{SO}_{2}$ which is obtained in normal air firing combustor. The higher $\mathrm{SO}_{2}$ capturing efficiency was resulted in fluidized combustor [1, 2 and 3]. They also revealed data which introduced the effect of operating conditions upon $\mathrm{SO}_{2}$ and $\mathrm{NO}_{x}$ emissions [1]. Guanghu et al. in 2013 simulated the $\mathrm{SO}_{2}$ and $\mathrm{NO}_{x}$ emission numerically for a fluidized bed combustor. They compared the theoretical results of sulfating reaction rate with which are presented in two different literatures. They introduced the reliable model to predict the $\mathrm{SO}_{2}$ emission and also temperature distribution in the combustor and riser [3 and 4].

Luis et al. in 2012, considered the membrane device instead of absorption contactors to recover $\mathrm{SO}_{2}$ from gas stream. Also, economic and environmental issues were studied for industrial contactor with ceramic hollow fiber membrane. They illustrated the dependency of economic estimation on environmental restrictions and the amount of $\mathrm{SO}_{2}$ in the inlet stream. So, the membrane technology doesn't meet the appropriate capacity which was obtained using contactors in $\mathrm{SO}_{2}$ recovery industries, yet [5].

In the literatures, conceptual design details and economic factors have been surveyed for the treatment of $\mathrm{SO}_{2}$ effluents from power plant or oil refinery with recovery of sulfur as by-product [5 and 6]. The preliminary requirements for removing $\mathrm{SO}_{2}$ from gas streams are simulating boiler flue gas or incinerated Claus plant effluents which have been assessed in continuous pilot plant. Continuous removal of $\mathrm{SO}_{2}$ in a slipstream from an oil-fired power boiler was achieved through metal oxides bed which expands to about double on fluidization at special flue gas rates [1,2 and 7]. Natural gas or hydrogen from coal is the basic reluctant for conversion of the adsorbed sulfuric acid to sulfur [4].

Application of dry fluidized activated carbon process is being developed at the continuous pilot stage for recovery of $\mathrm{SO}_{2}$ from flue gases as elemental sulfur. The $\mathrm{SO}_{2}$ component is removed from gases as sulfuric acid on metal oxides by sorption, catalytic oxygenation and hydrolysis. This is accomplished in a fluidized bed sorbent cooled to $1648.9^{\circ} \mathrm{C}$ by water sprays at $65.5^{\circ} \mathrm{C}$. An important development is the direct conversion of sorbent sulfuric acid to elemental sulfur by reaction with internally produced hydrogen sulfide. Conceptual design compares favorably with published Figures on alternate measures to control $\mathrm{SO}_{2}$ emissions [1, 2, 3 and 4].

The performance of fluidized bed reactor affects mainly the yield of $\mathrm{SO}_{2}$ recovery from effluent gases of sulfur production unit. In addition, conventional technologies require high level of energy. The superiority of this work is introducing a catalytic bed which is filled with zinc oxide nano catalyst to remove the $\mathrm{SO}_{2}$, feasibly and viably. So, in this paper, a zinc oxide catalytic bed is considered as a main part in $\mathrm{SO}_{2}$ removal unit which is fed by effluent gases of sulfur production unit.

\section{Materials and Method}

\subsection{Pilot Plant Experiences}

Pilot plant sets up to verify the mathematical model. A catalytic bed reactor is applied for $\mathrm{SO}_{2}$ adsorption process in this work. A Schematic of the nano layers is shown in the Figure 1.

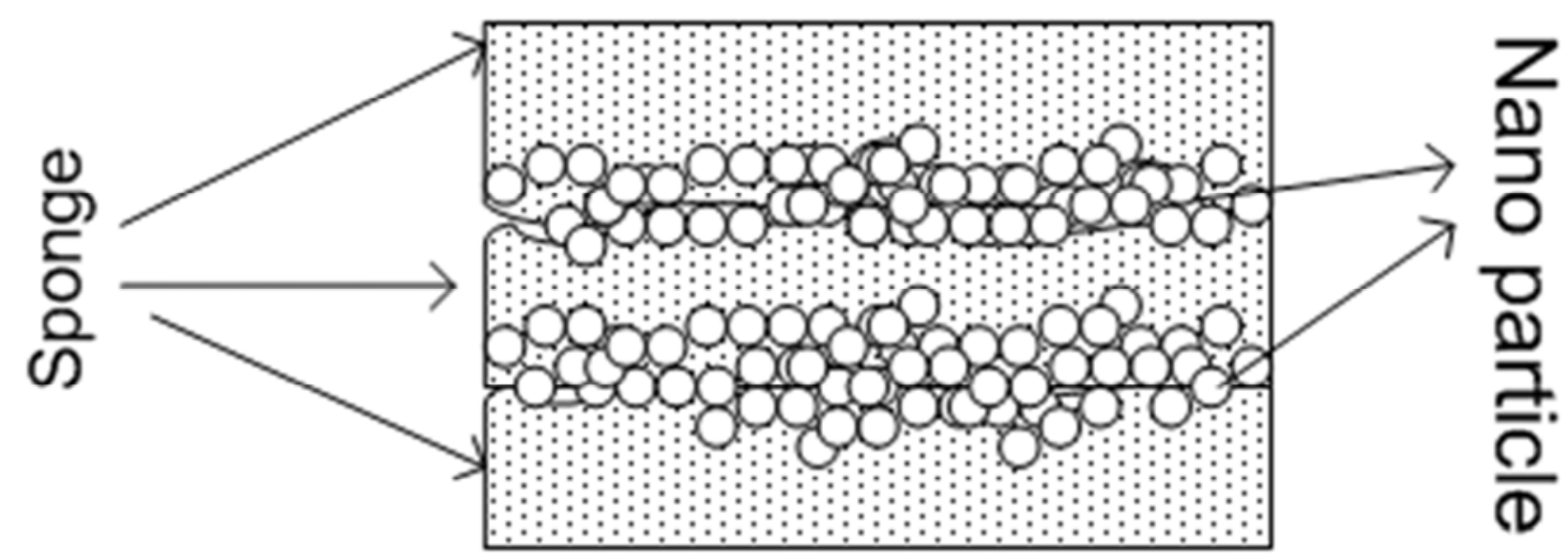

Figure 1. Schematic of distributed nano particles on the layer.

The flue gas enters the experimental reactor with a known amount of $\mathrm{SO}_{2}$. The $\mathrm{SO}_{2}$ reacts with catalyst in the reactor and the amount of $\mathrm{SO}_{2}$ in gas decreases while passing through the bed, gradually. The amount of $\mathrm{SO}_{2}$ in feed gas stream and the outlet stream is measured by the standard method which is described in literature. In addition, bed temperature, pressure and inlet gas velocity is measured 
in each experiment.

\subsection{Process Chemistry}

Gas stream enters the reactor which contains zinc oxide nano catalytic bed. Zinc reacts with oxygen which is in the gas stream into the zinc oxide. Then zinc oxide reacts with $\mathrm{SO}_{2}$ and $\mathrm{O}_{2}$ or with $\mathrm{SO}_{3}$ to produce zinc sulfate according to the reactions 1 and 2 . The amount of activation energy required for reactions 1 is $22 \mathrm{~kJ} / \mathrm{mol}$. The adsorption of $\mathrm{SO}_{2}$ is considered in this work.

$$
\begin{gathered}
2 \mathrm{Zn}_{2} \mathrm{O}_{3}+6 \mathrm{SO}_{2}+3 \mathrm{O}_{2} \rightarrow 2 \mathrm{Zn}_{2}\left(\mathrm{SO}_{4}\right)_{3} \\
\mathrm{Zn}_{2} \mathrm{O}_{3}+\mathrm{SO}_{2} \rightarrow \mathrm{Zn}_{2} \mathrm{SO}_{3}+\mathrm{O}_{2}
\end{gathered}
$$

In the industrial scale, reduction process can be done to regenerate the catalyst. In the reduction process, zinc sulfate changes into the metal zinc and $\mathrm{SO}_{2}$ releases. Mixture of hydrogen and carbon monoxide or light hydrocarbons can be used instead of hydrogen in reduction process. Related reactions 3,4 and 5 show the reduction process in the catalytic bed.

$$
\begin{gathered}
\mathrm{Zn}_{2}\left(\mathrm{SO}_{4}\right)_{3}+3 \mathrm{H}_{2} \rightarrow 2 \mathrm{Zn}+3 \mathrm{H}_{2} \mathrm{SO}_{4} \\
\mathrm{Zn}_{2}\left(\mathrm{SO}_{4}\right)_{3}+6 \mathrm{CO} \rightarrow 2 \mathrm{Zn}(\mathrm{s})+3 \mathrm{SO}_{2}+6 \mathrm{CO}_{2} \\
\mathrm{Zn}_{2}\left(\mathrm{SO}_{4}\right)_{3}+\mathrm{CH}_{4} \rightarrow 2 \mathrm{Zn}(\mathrm{s})+3 \mathrm{SO}_{2}+\mathrm{CO}_{2}+2 \mathrm{H}_{2} \mathrm{O}+\mathrm{O}_{2}
\end{gathered}
$$

Also, the zinc oxide and zinc sulfate vanishes nitrogen oxide compounds selectively in fluidized bed as catalysts. Therefore, $\mathrm{NH}_{3}$ is injected into the flue gas stream before entering the fluidized bed and then reacts with nitrogen oxide compounds in catalytic bed in contact with catalysts as are shown in reactions 6 and 7 .

$$
\begin{gathered}
4 \mathrm{NO}+4 \mathrm{NH}_{3}+\mathrm{O}_{2} \rightarrow 4 \mathrm{~N}_{2}+6 \mathrm{H}_{2} \mathrm{O} \\
6 \mathrm{NO}_{2}+8 \mathrm{NH}_{3} \rightarrow 7 \mathrm{~N}_{2}+12 \mathrm{H}_{2} \mathrm{O}
\end{gathered}
$$

\section{Results and Discussion}

\subsection{The Mass Flux Evaluation}

Parameters as temperature and pressure which are categorized as operation condition are the major consideration to evaluate the contaminant removal performance from gas. The adsorption mechanism is promoted by the increase in pressure and decrease in temperature. Total amount of mass transfer in term of $\mathrm{N}_{\mathrm{A}}$, $\mathrm{mol} / \mathrm{m}^{2} . \mathrm{s}$, is presented for this investigation. The amount of mass which is transferred by chemical reaction and also physical adsorption which equals with the amount of $\mathrm{N}_{\mathrm{A}}$ is altered by temperature and pressure. Also, in the other step the bed characteristics includes occupation volume, specific surface area and nano particle diameter are considered. Finally, the rate of feed stream as superficial velocity of gas is changed and the amount of NA is evaluated. Modelling results verified by the experimental data in each case.

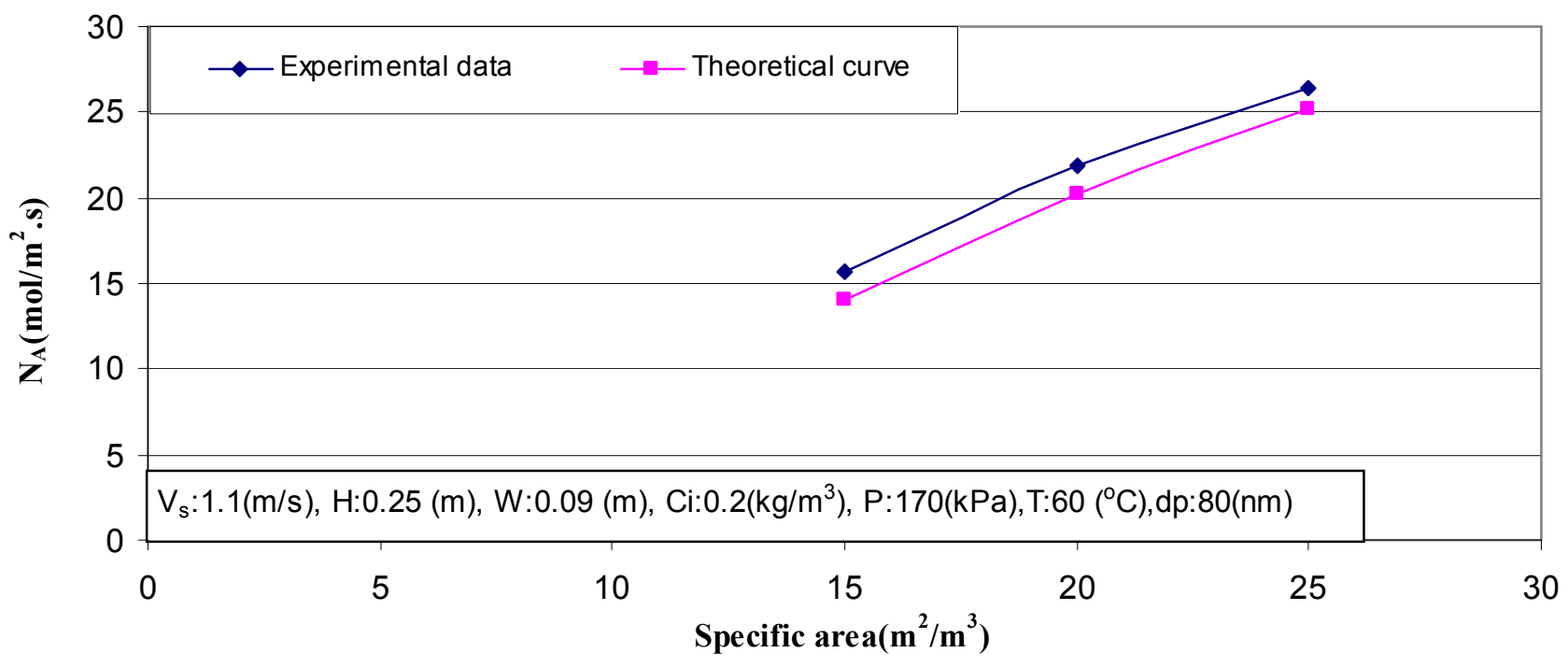

Figure 2. NA versus specific area.

The Figure 2 shows the effect of specific area on the mass flux. Geometerical property of catalytic bed is considered as values of different 15,20 and $25 \mathrm{~m}^{2} / \mathrm{m}^{3}$ of specific area. The effect of this physical property on the amount of NA is shown in the Figure 2. Specific area indicates on the catalytic area in a constant bed volume. The increase in the amount of specific area increases the amount of mass transfer representative, NA.

This can be related to the higher value of mass transfer area which leads to the higher amoun of mass transfer rate. 


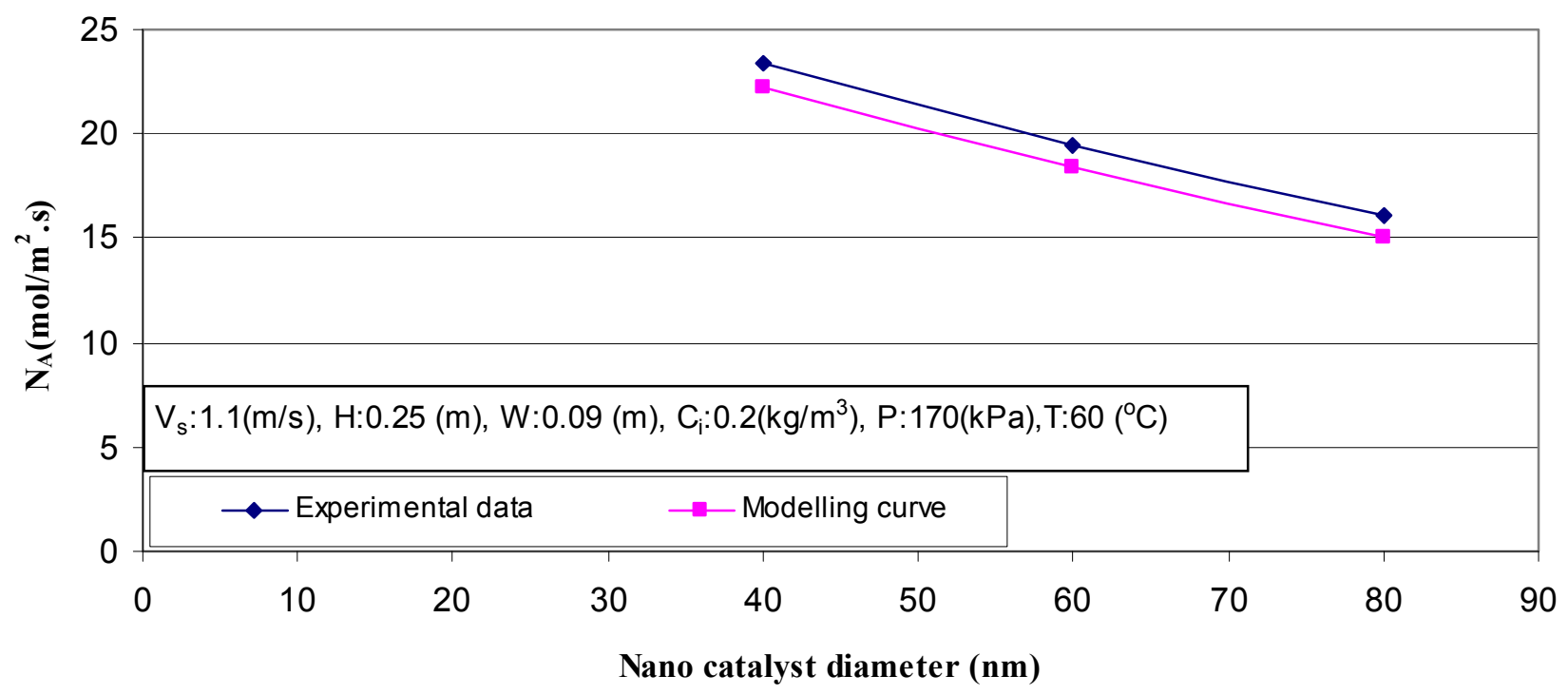

Figure 3. NA versus particle diameter.

Catalyst specification can be shown by the value of particle diameter. The influence of particle diameter on the amount of mass transfer rate is shown in Figure 3. Diameter of particle changes in values of $40 \mathrm{~nm}, 60 \mathrm{~nm}$ and $80 \mathrm{~nm}$. The higher diameter decreases the amont of mass transfer rate. This may since of the lower solid mass transfer resistance which is introduced by the smaller diameter of catalyst. The decreaes in diameter as $100 \%$ increases the value of NA about $60 \%$. The experimental results shows good agreement with modelling ones.

\subsection{The Operating Conditions Evaluations}

The equations 1 and 2 show the effect of operating temperature and operating pressure as two major items on the sweetening process. These parameters state the evaluation of combination of operating pressure and operating temperature. The uncertainty of theses equations are very low. So these equations can be replaced by experimental costs.

$$
\begin{gathered}
60 C\left\langle T,(170 \mathrm{kPa}) \quad C / C_{0}=1.34 T^{2}+2.01 T+0.120\right. \\
\text { Uncertainty }=0.65 \% \\
T\left\langle 60 C,(170 \mathrm{kPa}) \quad C / C_{0}=1.78 T^{2}+1.983 T+0.419\right. \\
\text { Uncertainty }=0.54 \%
\end{gathered}
$$

\section{Conclusion}

The process quality and process behavior of $\mathrm{SO}_{2}$ removal adsorption in one cylindrical bed containing zinc oxide catalyst with $0.09 \mathrm{~m}$ width and $0.25 \mathrm{~m}$ height is studied, in this work. Physical mass transfer is evaluated by changes in some parameter of catalytic bed as bed volume occupation, catalyst diameter and bed specific area. Important operation conditions means temperature and pressure then are considered.

The performance of the process is shown as NA which is evaluated by the changes in some important parameters.
Briefly, the increase in the temperature, pressure, specific surface area, superficial velocity of gas and occupied volume increases the amount of mass transfer rate. The increase in catalytic bed diameter decreases the rate of mass transfer. The increase in the amount of catalyst diameter decreases the mass transfer area and this can be obtained by the theoretical and experimental results of NA. The nano catalyst diameter changes from $40 \mathrm{~nm}$ to $80 \mathrm{~nm}$ and this decreases the value of NA from about 23 to $16 \mathrm{~mol} / \mathrm{m}^{2} . s$, experimentally and from 22.2 to $15 \mathrm{~mol} / \mathrm{m}^{2} . \mathrm{s}$, theoretically. The effect of operating pressure and also, the operating temperature on the dioxide sulphure removal on the swteening process is evaluated by formulas 8 and 9 .

\section{References}

[1] L. Carlos, G. Isabel, B. Irene, D. Luis I., R. Luis M. Experimental study of $\mathrm{SO} 2$ and NOx emissions in fluidized bed oxy-fuel combustion. Fuel Process Techno., 2013; 106: $587-594$.

[2] M. de las Obras-Loscertales, A. Rufas, L. F. de Diego, F. García-Labiano, P. Gayán, A. Abad, J. Adánez, Effects of Temperature and Flue Gas Recycle on the $\mathrm{SO}_{2}$ and $\mathrm{NO}_{\mathrm{x}}$ Emissions in an Oxy-fuel Fluidized Bed Combustor, Energy Procedia., 2013; 37: 1275-1282.

[3] W. Kaewboonsong, V. I. Kuprianov, N. Chovichien, Minimizing fuel and environmental costs for a variable-load power plant (co-) firing fuel oil and natural gas: Part 1 . Modeling of gaseous emissions from boiler units, Fuel Processing Technology, 2006; 87: 1085-1094

[4] A. Irabien, Environmental and economic evaluation of $\mathrm{SO}_{2}$ recovery in a ceramic hollow fibre membrane contactor. Chem Eng Process: Process Inten., 2012; 52: 151-154.

[5] H. Wang, Sh. Li, F. Lai, B. Wang, Computational Model of Greenhouse Gas Emissions of Power Station boiler Considering Desulphurization, Physics Procedia, 2012; 24: 44-49. 
[6] D. L. Stern, K. E. Nariman, J. S Buchanan, N. A. Bhore, D. L. Johnson, R. K. Grasselli, The Mobil Oil $\mathrm{SO}_{\mathrm{x}}$ Treatment Process (MOST). Catalytic removal of $\mathrm{SO}_{x}$ and $\mathrm{H}_{2} \mathrm{~S}$ from refinery tail gas, Catalysis Today, 2000; 55: 311-316.

[7] W. Zhou, C. S. Zhao, L. B. Duan, XP. Chen, C. Liang, Twodimensional computational fluid dynamics simulation of nitrogen and sulfur oxides emissions in a circulating fluidized bed combustor. Chem. Eng. J., 2011; 173: 564-573.

[8] D. Eow, S. John, Recovery of sulfur from sour acid gas: A review of the technology Environmental Progress. Americ. Institut. Chem. Eng., 2002; 21: 143-162.

[9] D. Kunii, O. Levenspiel, Fluidization engineering. First edition. New York: Wiley; 1991.

[10] JF. Davidson, Fluidization. First edition. USA: Academic Press; 1991.
[11] D. Green, R. Perry. Perry's Chemical Engineers' Handbook. 8th edition, USA: Mc Graw Hill; 2007.

[12] W. Ch. Yang. Handbook of Fluidization and Fluid-Particle Systems. First edition. USA: Taylor \& Francis; 2003.

[13] L. Davidson, Jr Amick, H. Erwin, Formation of gas bubbles at horizontal orifices. AIChE J 2004; 2: 337-342.

[14] M. Uzi. Principles of chemical reactor analysis and design. second edition. New York: Wiley; 2009.

[15] O. Levenspiel, Chemical Reaction Engineering. 3th Ed. New York: Wiley; 1999.

[16] W. J. Reagan, F. M. Dautzenberg, Catalyst Analysis Using Syn- chrotron X-Ray Microscopy, Nucl. Instrum. Methods Phys. Res., 1991; 56/57: 427-432. 